RASĀYAN J. Chem.

Vol. 13 | No. 3 |1711-1718| July - September | 2020 ISSN: 0974-1496 | e-ISSN: 0976-0083 | CODEN: RJCABP

\title{
INFLUENCE OF POLARIZATION RATE ON LOCALIZED CORROSION OF STAINLESS STEEL USED IN GARBAGE COLLECTOR TRUCKS
}

\author{
J. Bautista-Ruiz ${ }^{1, *}$, A. Chaparro ${ }^{2}$ and G. Moreno-Contreras ${ }^{3}$ \\ ${ }^{1}$ Department of Electromechanical Engineering, Universidad Francisco de Paula Santander, San \\ José de Cúcuta-540005, Colombia \\ ${ }^{2}$ Department of Engineering, Universidad ECCI, Bogotá-11101, Colombia \\ ${ }^{3}$ Department of Mechanical Engineering, University of Pamplona, \\ Pamplona-543050, Colombia \\ *E-mail: g.ing.materiales@gmail.com
}

\begin{abstract}
The corrosion rate of SAE 5115 steel located inside a garbage compactor trucks and the corrosion products originated by an aqueous solution called leachates containing dissolved salts and heavy metals at room temperature and for exposure of five years were studied. We conducted accelerated trials using a contaminant such as the above-mentioned slurry. Microscopy techniques and polarization curves were used. Using microscopic techniques, the degree of advance was determined and correlated with the corrosion rate, determining the degree of deterioration due to pitting type corrosion, establishing a direct relationship between the rate of deterioration and the time of onset of pitting corrosion in contact with leachates.
\end{abstract}

Keywords: Corrosion, Pitting, Leachates, Corrosion Rate.

(C) RASĀYAN. All rights reserved

\section{INTRODUCTION}

The corrosion in the steels causes damages that can lead to accidents, even though new alloys have been developed; the best cost/durability ratios have not been established with precision. As a result, when constructing parts for garbage collection vehicles, it is difficult to establish the metal alloy that provides the greatest durability of the parts when in contact with corrosive agents such as leachates generated by the decomposition processes of organic waste present in the garbage.$^{1-3}$ However, the need to study further and determine the factors that influence the selected alloy must be argued once again. Potential pitting corrosion damage in steels depends critically on the percentage of manganese, nickel and chromium composition. ${ }^{4,5}$ Also, the corrosive attack process is also affected by properties such as, the sulfur which in the case of ductility decreases when hot in duplex stainless steel, in which the dependence of the behavior of the steel with the contents of some part per million ( $\mathrm{ppm}$ ) of sulfur takes place not only by the insoluble sulfur (in the form of sulfides) but also by that of the soluble sulfur present in crystalline nets as a substitutional element. ${ }^{6-9}$

The pitting potential $\left(\mathrm{E}_{\mathrm{pit}}\right)$ is often used as an accelerated laboratory test to determine the susceptibility of iron-based alloys to localized corrosion in chloride media. ${ }^{10-17}$ The higher the $\mathrm{E}_{\mathrm{pit}}$ value for a given potential sweep rate, the less susceptible the material is to the initiation of a localized corrosion phenomenon. $\mathrm{E}_{\mathrm{pit}}$ value is dependent on various factors such as the medium and alloy composition. Research has been done to clarify the relationship between $\mathrm{E}_{\mathrm{pit}}$ value and steel composition; but so far, no satisfactory explanation has been found. ${ }^{18,19}$

This research aims to determine the relationship between pitting potential and polarization velocity in SAE 5115 steel samples when the current density exceeds a critical value. Advanced techniques have been used to assess leachate damage and establish the cause of the increased corrosion rate. 
RASĀYAN J. Chem.

Vol. 13 | No. 3 |1711-1718| July - September | 2020

\section{EXPERIMENITAL}

The SAE 5115 Low Alloy Steel studied has been commercialized with the following mass composition (\%): $0.135 \mathrm{C} ; 0.950 \mathrm{Mn} ; 0.18 \mathrm{P} ; 0.006 \mathrm{~S} ; 0.19 \mathrm{Si} ; 0.008 \mathrm{Cu} ; 0.072 \mathrm{Ni} ; 0.190 \mathrm{Cr} ; 0.015 \mathrm{~V} ; 0.046 \mathrm{Mo} ; 0.032$ W; $0.023 \mathrm{Co}$; $0.006 \mathrm{Ti} ; 0.007 \mathrm{Sn} ; 0.062 \mathrm{Al} ; 0.025 \mathrm{Nb} ; 0.016 \mathrm{~Pb}$, and $98.066 \mathrm{Fe}$. Specimens of $11 \mathrm{~cm}^{2}$ surface area were cut and polished with $\mathrm{SiC}$ paper, up to 1200 grain.

An EG\&G PARC 273A potentiostat-galvanostat was used to evaluate corrosion resistance; Tafel diagrams were obtained at a sweep speed of $0.16 \mathrm{mV} / \mathrm{s}$ over a voltage range of one hour's immersion in the solution whose components are shown in Table-1, starting at the open circuit potential $(\sim 0.25$ VESC) and ending in the pitting region ( $0.5 \mathrm{VESC}$ ). The electrolyte used was an aqueous solution of $5 \% \mathrm{NaCl}$ (pH $\sim 8$ ), using an exposed area of $1 \mathrm{~cm}^{2}$. The molar mass of the working electrode (Ew) for all measurements was assumed to be $55.847 \mathrm{~g} / \mathrm{mol}$ taking into account pure $(\mathrm{Fe})$ as a reference since this material $(\mathrm{Fe})$ has low carbon content. A reference electrode $(\mathrm{Ag} / \mathrm{AgCl})$ and a platinum mesh of $36 \mathrm{~cm}^{2}$ were used as reference and counter electrodes, respectively.

Table-1: Electrolyte Composition

\begin{tabular}{c|c}
\hline Component & $(\mathrm{mg} / \mathrm{l})$ \\
\hline Calcium & 950 \\
\hline Chlorine & 520 \\
\hline Sodium & 486 \\
\hline Nitrogen & 325 \\
\hline Potassium & 305 \\
\hline Sulfates & 295 \\
\hline Iron & 95 \\
\hline Phosphorus & 52 \\
\hline
\end{tabular}

For the evaluation of wear resistance to substances such as leachates, rotary cylinder-type equipment was used, consisting of a glass container in which the solution is contained, an acrylic lid in which the reference electrode, the counter electrode, and the sample holder are arranged with an exposure area of the sample of $1 \mathrm{~cm}^{2}$.

The surface characterization was made by optical microscopy. The topography of the coating was analyzed using a scanning electron microscope brand FEI Tecani F20 FEG-TEM. Structural characterization was analyzed by X-Ray diffraction (XRD) with a Philips X-ray diffractometer, with Bragg-Brentano configuration $(\theta / 2 \theta)$ in the ground beam mode, $\mathrm{Cu} \mathrm{K \alpha}$ radiation $(\lambda=1.5405 \AA)$.

\section{RESULTS AND DISCUSSION}

Figure-1(a) shows a scheme of a garbage truck. Figure-1(b) shows the damage caused by leachate in the compacting box of the waste collection vehicle. The deterioration of the steel structure is due to the phenomenon of pitting corrosion.

A more rigorous analysis of the metal surface is shown in Fig.-2. Damage to the metal surface caused by contact with leachate is evident (Fig.-2a). Figure-2b shows in detail a type of localized attack manifested as perforations in the metal plate.

The development of the analysis began with a visual inspection of the metal plates that have been in contact with the leachate, as mentioned above. Next, samples were sectioned for morphological observation, and then procedures were developed according to ASTM G5 $-87^{20}$. Subsequently, samples obtained from areas close to those affected and revealing wear were prepared. Corrosion deposits and other constituents of the metal plate surface were analyzed. At the same time, the back of the plate was analyzed with two treatments, one without removing the protective layer and the other removing the protective layer by mechanical polishing until the surface of the SAE 5115 steel was exposed.

Inspection of the plate after wear was detected, (Fig.-2) revealed corrosion on the surface exposed to the leachate. The presence of brown corrosion products deposited on the external and intermediate surface of the holes is observed. Afterward, several cuts are made to evaluate them with the technique of potentiodynamic polarization curves to determine the rate of deterioration. 
RASĀYAN J. Chem.

Vol. 13 | No. 3 |1711-1718| July - September | 2020

Figure-3 shows three potentiodynamic polarization curves of SAE5115 steel samples when immersed in the solution simulating the leachate. The passivity filler at current density, $\sim 10^{-7} \mathrm{~A} \mathrm{~cm}^{-2}$, is presented for the sample that has a protective oxide film. However, this film is unstable due to increased corrosion current density when the anodic potential varies. ${ }^{21}$

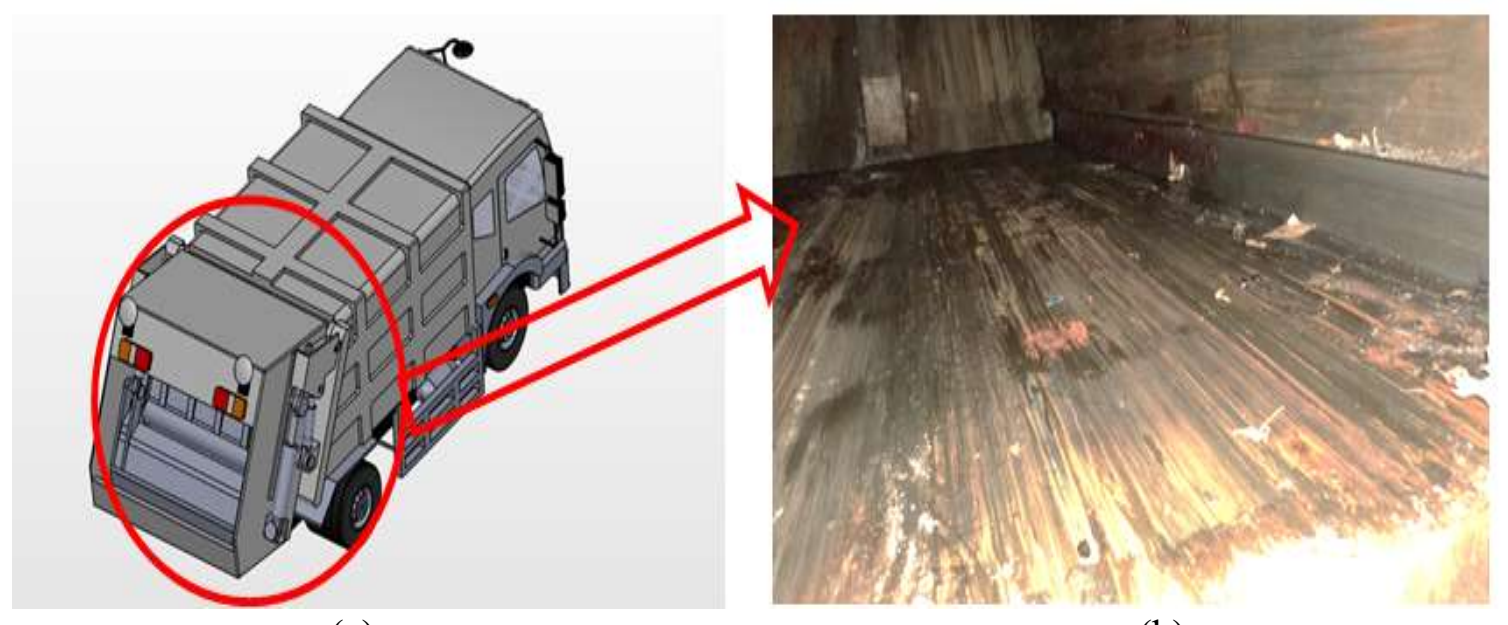

(a)

(b)

Fig.-1: Basic Aspects of a Garbage Truck (a) Diagram of the Garbage Truck and (b) Detail of the Corrosion Damage in the Garbage Compactor.

The steels were evaluated at different speeds and taken as representative samples one from the floor of the truck structure (red curve, Fig.-3) and the other from the wall (black curve, Fig.-3). The results indicate the same behavior established by low stability. This result explains why the anodic region shows a low passivity potential range, followed by an increase in the corrosion current indicating the existence of pitting corrosion phenomena caused by the presence of chloride ions, the $\mathrm{pH}$ value and the reduction-oxidation potentials. These factors can cause the rupture of the passive film and subsequent attack on the substrate.

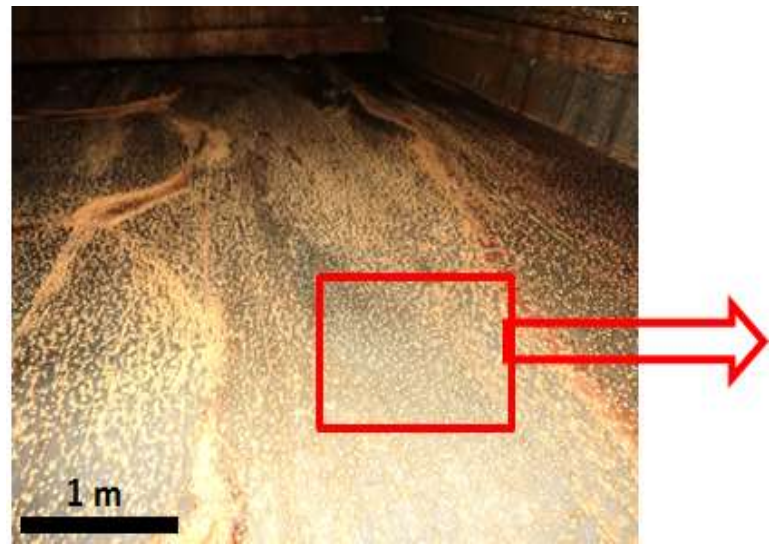

a)

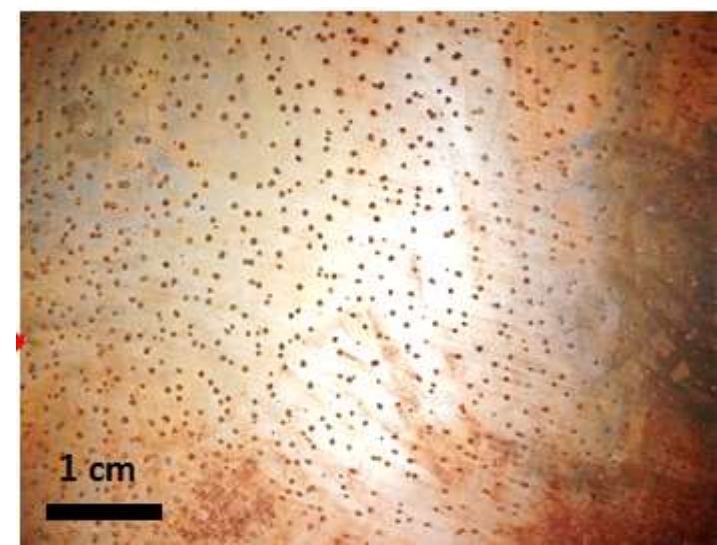

(b)

Fig.-2: Corrosion Damage to the Compactor Box Section of a Garbage Truck. (a) General View and (b) Detailed View.

Leachates generate a reducing capacity due to their high pollutant factor, due to the content of organic matter and heavy metals of which they are composed. In the polarization curves, it is observed that at 100 $\mathrm{mV}$, in the anodic region, there is an increase in the current density when the potential reaches the critical value $\left(\mathrm{E}_{\mathrm{pit}}\right.$ ), the current density ${ }^{22}$ is $\sim 10^{-3} \mathrm{~A} \mathrm{~cm}^{-2}$. A proportional behavior between the increase in corrosion velocity and the pitting corrosion current density values can be evidenced. The results allow for a decrease in four orders of magnitude of the system without a protective layer concerning the system protected by the layer, this situation leads to increased corrosion current density. 
RASĀYAN J. Chem.

Vol. 13 | No. 3 |1711-1718| July - September | 2020

The previous analysis allows one to establish that the type of wear in the steel sheet is generated by accelerated corrosion phenomena. The existence of two classes of zones is evidenced (Fig.-2), one in which there is no accumulation of particles and the other zone corresponds to the deteriorated region related to excessive material detachment. The deterioration speed for the specimen with a protective oxide layer is 0.028 mpy (milli-inch per year). The results establish a similarity for steel specimens that present deterioration caused by corrosive processes and samples subjected to surface polishing; the values established in these conditions are 0.392 mpy and 0.283 mpy, respectively.

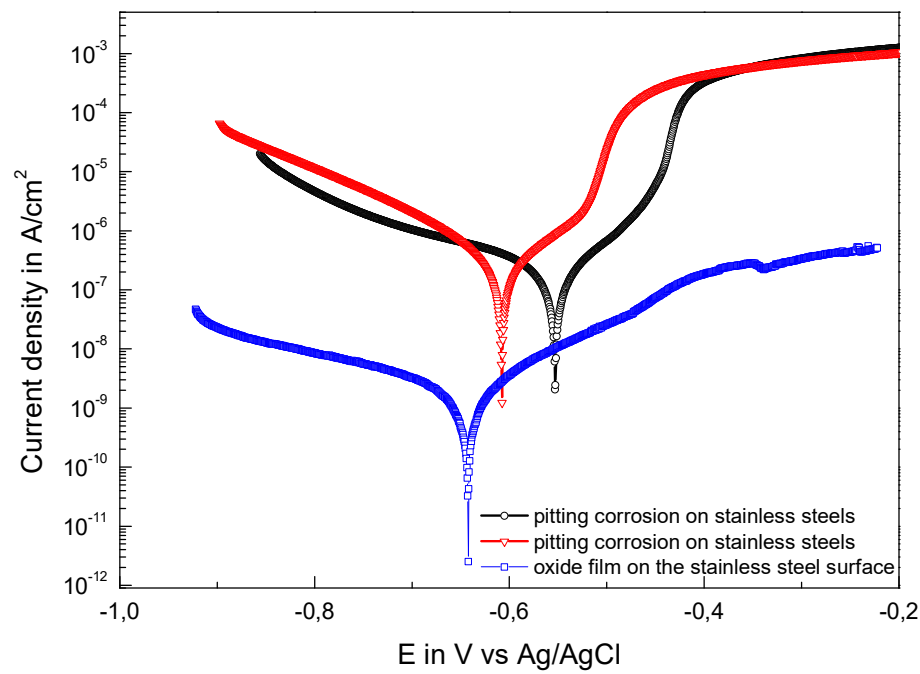

Fig.-3: Polarization Curves, Where Systems with and without Protection are Evaluated and their response in Pitting Potential $\left(\mathrm{E}_{\mathrm{pic}}\right)$ and Pitting Current Density of Steel.

Figure-4 shows the X-ray diffraction pattern for SAE 5115 steel without any leachate attack. An intense peak is observed at $2 \theta=45^{\circ}$ corresponding to the diffractions in the planes (110) indicating a high degree of crystallinity of the substrate in this orientation. Also, other peak with lower intensity is evidenced at $2 \theta$ $=70^{\circ}$ and is associated with diffraction in the planes (220).

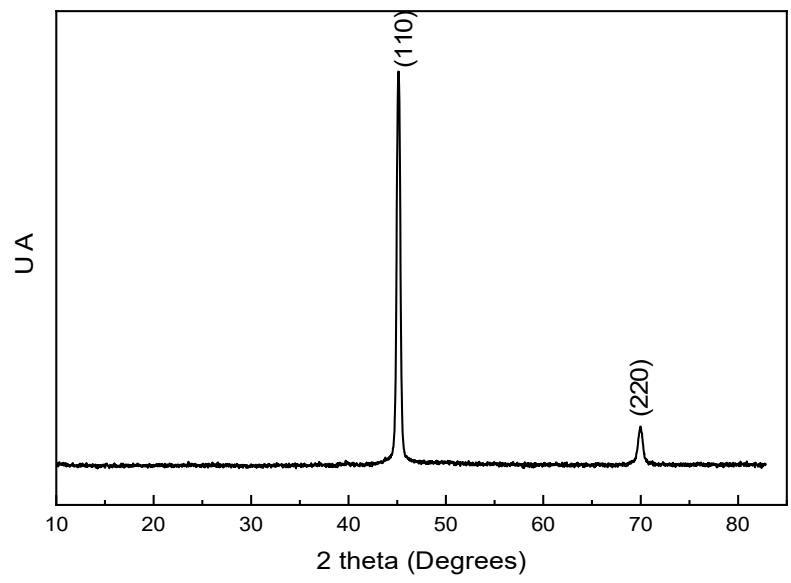

Fig.-4: X-ray Diffraction Spectrum, Corresponding to SAE5115 Steel Substrate.

Figure-5 shows the X-ray diffraction pattern for SAE 5115 steel after exposure to leachate degradation. Three oxidizing elements related to peaks are obtained at $2 \theta=30^{\circ}, 40.47^{\circ}$ and $76.25^{\circ}$, associated to the 
RASĀYAN J. Chem.

Vol. 13 | No. 3 |1711-1718| July - September | 2020

crystallographic planes (012), (104) and (214), respectively. The compositional analysis from the previously related peaks allows the semi-quantitative determination of the concentration of oxides present. The results of the topographic evaluation by SEM are observed in the micrographs in Fig.-6. There are areas affected by corrosive processes as a result of corrosion tests. This type of corrosion occurs when there are anodic and cathodic regions with a difference in electrochemical potential, originated by ion exchange by immersion in the electrolytic medium (leachate) ${ }^{23}$. For the characterization of the corrosion products, the area marked with red is chosen in Fig.-6. The result of the analysis is the presence of iron oxides and chlorine (hypochlorous anhydride). The pitting corrosion is attributed to the presence of chloride ions. This type of ions promotes the breakage of the passivizing layer in localized areas of the metallic surface, which is consistent with the formation of small holes evidenced in Fig.-2a.

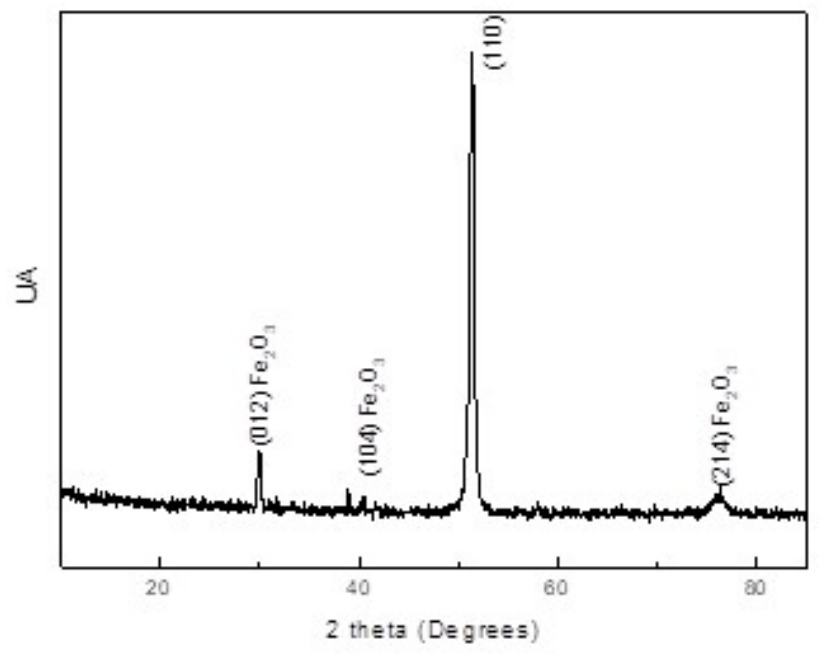

Fig.-5: X-ray Diffraction Spectrum, Corresponding to Steel after Exposure to Degradation in a Leachate Medium.

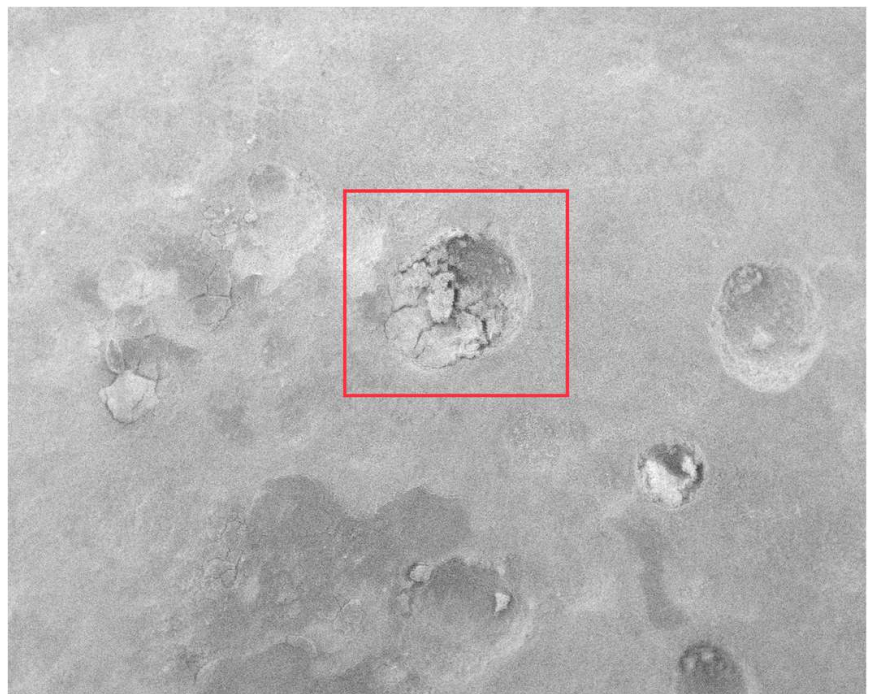

Fig.-6: Micrograph with Composition Analysis Corresponding to the Area with Oxide Layer.

Figure-7 shows the results on the metal surface due to prolonged exposure to leachate. A high degree of wear is determined related to the perforations generated by the anodic zones. As previously mentioned, 
RASĀYAN J. Chem.

Vol. 13 | No. 3 |1711-1718| July - September | 2020

visual inspection allows determining a localized or pitting corrosion process, after exposing the metal with the leachate and developing accelerated corrosion tests. From the results, it can be inferred that the presence of oxidizing agents in an environment composed of chlorides is generally very harmful and will favor pitting corrosion processes ${ }^{19}$. The oxidizing agent, chloride ion, increases the probability of pitting corrosion by providing additional cathodic reagents and increasing the overall local potential. It is determined that metal, SAE 5115 steel, in contact with leachates does not generate passivizing layers. Pitting corrosion is considered accelerated in nature, that is, when a pitting starts to grow, the local conditions are altered in such a way that the growth of the pitting is promoted.

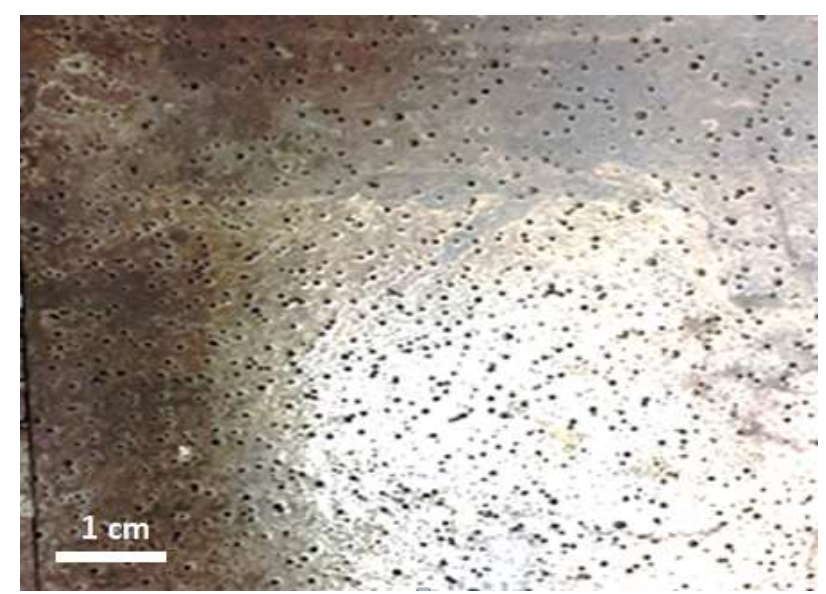

Fig.-7: Metal Sample after Prolonged Exposure to Leachate Attack.

Figure-8(a) shows the posterior region of the analyzed steel specimen. The initial visual inspection makes it possible to establish that there is no localized corrosion or pitting. By exposing the metal with the leachate and performing accelerated corrosion tests in a chloride environment, the presence of very harmful oxidizing agents is observed that favor pitting corrosive processes (Fig.-8b). The micrograph shows areas that do not present corrosion problems. This indicates the absence of agents due to the protective layer of the steel material. However, by making contact and abrasion, a function performed by the garbage compactor carriage, it is not possible that this coating is resistant to localized corrosion. It is also important to point out that the presence of this protective layer in the system can induce passivity, as can be seen in Figure $8 b$ ) where the phenomenon of localized corrosion is minimal.

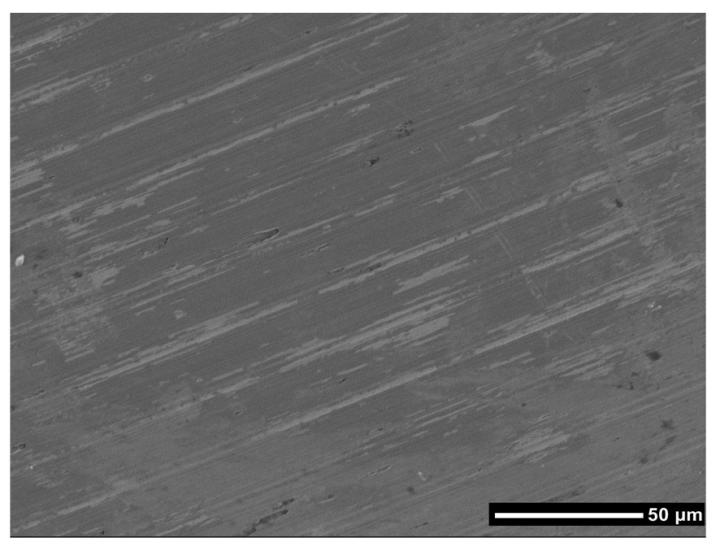

(a)

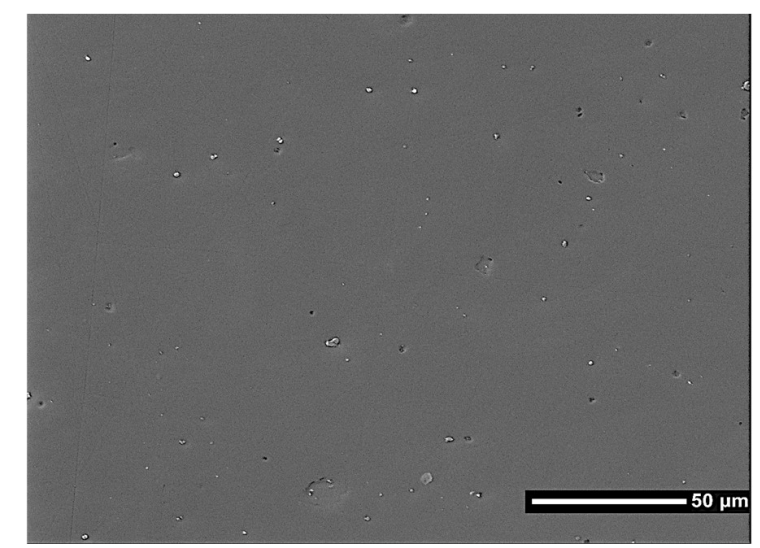

(b)

Fig.-8: Micrographies of the Areas that do not present Corrosion Problems.

\section{CONCLUSION}

The visual, physicochemical and metallurgical inspection analyses performed on the sheet that showed damage due to localized corrosion, showed a high level of wear and tear; this type of corrosion, most likely, was caused by contamination with leachate solution. 
There is a high content of corrosion products such as oxides and chloride ions that make up the leachate. These conditions cause damage to the mechanical parts and decrease their useful life due to low corrosion resistance.

There is a direct relationship between the pitting potential generated on the surface of the steel that has lost passivity and degradation speed because the surface with protection and without active corrosion processes generates low corrosion density values close to $10^{-7} \mathrm{~A} \mathrm{~cm}^{-2}$, and those that have already been put into operation generate values of $10^{-5} \mathrm{~A} \mathrm{~cm}^{-2}$, which increases two orders of magnitude, and is triggered by the presence of pitting corrosion, this increases the deterioration in an accelerated manner.

\section{ACKNOWLEDGEMENT}

To Universidad Francisco de Paula Santander, Universidad ECCI, and Universidad de Pamplona.

\section{REFERENCES}

1. B. Okonkwo, H. Ming, Z. Zhang, J. Wang, E. Rahimi, S. Hosseinpour and A. Davoodi, Corrosion Science, 154, 49(2019), DOI:10.1016/j.corsci.2019.03.027

2. A. Dehghani, G. Bahlakeh, B. Ramezanzadeh and M. Ramezanzadeh, Journal of Molecular Liquids, 277, 895(2019), DOI:10.1016/j.molliq.2019.01.008

3. A. Dehghani, G. Bahlakeh, B. Ramezanzadeh and M. Ramezanzadeh, Journal of Molecular Liquids, 279, 603(2019), DOI:10.1016/j.molliq.2019.02.010

4. Q. Xin and C.F. Pinzon, 2014, Improving the environmental performance of heavy-duty vehicles and engines: key issues and system design approaches, in R. Folkson (Eds.), Alternative Fuels and Advanced Vehicle Technologies for Improved Environmental Performance, Woodhead Publishing, Cambridge, pp. 225-278.

5. B. Xie, Y. Li and L. Jin, Procedia - Social and Behavioral Sciences, 96, 945(2013), DOI: $10.1016 /$ j.sbspro.2013.08.108

6. J. Verma and R. Vasantrao-Taiwade, Journal of Manufacturing Processes, 25, 134(2017), DOI: 10.1016/j.jmapro.2016.11.003

7. C. Farias, H. Boschetti, S. Wolynec and A. Padilha, Engineering Failure Analysis, 97, 161(2019), DOI: 10.1016/j.engfailanal.2018.12.009

8. Q. Ma, C. Wu, G. Cheng, F. Li, Materials Today: Proceedings, 2, 300(2015), DOI: 10.1016/j.matpr.2015.05.042

9. Y. Hu, S. Tang, A. George, Z. Tao, X. Wang and H. Thai, Journal of Constructional Steel Research, 157, 371 (2019), DOI: 10.1016/j.jcsr.2019.02.021

10. L. Guo, S.R. Street, H. Mohammed-Ali, M. Ghahari, N. Mi, S. Glanvill, A. Du-Plessis, C. Reinhard, T. Rayment and A. Davenport, Corrosion Science, 150, 110(2019), DOI:10.1016/j.corsci.2019.01.033

11. H. Ha, T. Lee, C. Lee and H. Yoon, Corrosion Science, 149, 226(2019), DOI: 10.1016/j.corsci.2019.01.001

12. D. Guo, C.T. Kwok and S.L.I. Chan, Surface and Coatings Technology, 361, 324(2019), DOI:10.1016/j.surfcoat.2019.01.055

13. L. Wang, J. Xin, L. Cheng, K. Zhao, B. Sun, J. Li, X. Wang and Z. Cui, Corrosion Science, 147, 108(2019), DOI: 10.1016/j.corsci.2018.11.007

14. R. Thilagavathi, A. Prithiba and R. Rajalakshm, Rasayan Journal of Chemistry, 12(2), 431(2019), DOI: $10.31788 /$ RJC.2019.1225133

15. S. Jyothi, Y.V. Subba Rao and P.S. Samuel Ratnakumar, Journal of Chemistry, 12(2), 537 (2019), DOI: $10.31788 /$ RJC.2019.1225000

16. S. Agiladevi, and S. Rajendran, Rasayan Journal of Chemistry, 12(1), 22(2019), DOI: 10.31788/RJC.2019.1215037

17. J. Bautista-Ruiz, W. Aperador and J.J. Olaya, Rasayan Journal of Chemistry, 11(2), 597(2018), DOI: $10.31788 /$ RJC.2018.1122075

18. X. Feng, X. Zhang, Y. Xu, R. Shi, X. Lu, L. Zhang, J. Zhang and D. Chen, Engineering Failure Analysis, 98, 49(2019), DOI:10.1016/j.engfailanal.2019.01.073 
RASĀYAN J. Chem.

Vol. 13 | No. 3 |1711-1718| July - September | 2020

19. M. Dai, J. Liu, F. Huang, Y. Zhang and Y. Cheng, Corrosion Science, 143, 428(2018), DOI: 10.1016/j.corsci.2018.08.040

20. ASTM G5-14e1, 2014; Standard Reference Test Method for Making Potentiodynamic Anodic Polarization Measurements, in: ASTM International (Eds.), New York, pp. 281-296, DOI: $10.1520 / \mathrm{G} 0005-14 \mathrm{E} 01$

21. J. Aramendia, L. Gomez-Nubla, I. Arrizabalaga, N. Prieto-Taboada, K. Castro and J.M. Madariaga, Corrosion Science, 76, 154(2013), DOI:10.1016/j.corsci.2013.06.038

22. C. Nicard, C. Allély and P. Volovitch, Corrosion Science, 146, 192(2019), DOI: $10.1016 /$ j.corsci.2018.10.037

23. J.S. Moya, B. Cabal, J. Sanz, A.C. da Silva, S. Mello-Castanho, R. Torrecillas and F. Rojo, Materials Letters, 70, 113(2012), DOI:10.1016/j.matlet.2011.11.104

[RJC-5521/2019] 